\title{
Strengthening of steel-concrete composite beams in experimental study
}

\author{
P. Szewczyk \\ Faculty of Civil and Environmental Engineering, West Pomeranian University of Technology, Szczecin, \\ Poland \\ M. Szumigała \\ Faculty of Civil and Transport Engineering, Poznan University of Technology, Poznań, Poland
}

\begin{abstract}
The paper presents selected results of experimental research performed on steel - concrete composite beams. The study aimed at determining efficiency and technical feasibility of strengthening such structures. The main assumption was that strengthening was conducted under load, which is consistent with the factual state of the modernized structure. Beams were strengthened by welding sheet metal to increase the area of the steel section. The safe level of stress during welding and the appropriate order of joints were determined. The study focused on distortion caused by welding, cooling and shrinkage. Following the strengthening, the beams were overloaded, underwent plastic distortion and were ultimately damaged. The beams' increased stiffness and capacity due to strengthening was monitored.
\end{abstract}

\section{INTRODUCTION}

Structures must be strengthened for a variety of reasons; due to design errors, workmanship defects, wrong exploitation, vibration or lack of proper maintenance. On the other hand, the need to strengthen can be triggered by changes in the way a structure is used, by changes in technology or by a different purpose the structure is supposed to serve. In each of the above situations, attention should be paid that modernization is conducted on an already existing construction, i.e. one that carries at least its own constant weight and possibly service and technological load. It would be ideal to completely relieve a structure of any load to design the strengthening as one designs brand new objects. However, that would require to remove any elements that load the object. It would be expensive and time-consuming. Putting up shoring posts would be another way to deal with the problem. That would, however, take up space below. Sometimes, it is not possible to remove the service load. Compare an interesting object, discussed in the following papers (Paczkowski, Wróblewski \& Skibicki, 2020), (Wierzbicki et al., 2020). Therefore, in most cases it is fair to assume that a strengthened structure has a certain actual stress ratio, which sometimes can be significantly high.

Steel structures are suitable to be strengthened (Liu and Gannon, 2009), (Wang et al., 2015), (Ali, Kvočák \& Platko, 2017). Elements that are strengthened and strengthening parts can be welded and stress can be plastically redistributed. However, welding operations involve additional distortion and weld shrinkage. The magnitude of these effects depends on the sign and level of stress in the welded place,

The present study tried to take into account all the above factors. A steel-concrete composite beam was taken as the research model. Owing to the composite character of the beam's 
cross-section which involves both plastic, ductile steel and brittle concrete, its analysis poses significant challenges.

\section{EXPERIMENTAL RESEARCH}

\subsection{Research model}

A steel-concrete composite beam with a cross-section presented in Figure 1 was adopted as the research model. The beam's dimensions were chosen so that its neutral axis was close to the joint's area. The beam was analyzed in a simply supported system, with the spacing between supports of $5 \mathrm{~m}$. This static scheme provided a classic division between a compressed concrete and a stretched steel part. The flexible reinforced concrete (C25/30 concrete, Bst500 reinforcement) was connected to the steel (S235JR) with SD stud connectors. In all the tests, a 10x120 mm flat bar was welded to the bottom flange of IPE200 beam. Because the width of the flat bar was greater than the width of the flange by $20 \mathrm{~mm}$, the elements were welded in a preferable PB horizontal vertical position. The length of the sheet metal stiffener was smaller than the distance between the supports and it was 3,200 $\mathrm{mm}$. A comprehensive analysis of the optimal choice of strengthening plate can be found in (Szewczyk and Szumigała, 2016).

\subsection{Strengthening under load}

The first step was the introduction of preload to simulate the tension before reinforcement. The load was supposed to be reduced so that at each stage of reinforcement the ultimate limit state would be met. When a structure is welded, its cross-section is locally weakened. This weakening can be taken into account by the reduced cross-sectional area. The reduction of the area occurs in the place where the structure gets hot. Its range depends on the linear energy of electric arc $q_{l}$. The welding was done using 111 method: $140 \mathrm{~A}$ current, $28 \mathrm{~V}$ voltage, $3 \mathrm{~mm} / \mathrm{s}$ welding velocity. Owing to the type of steel used (S235JR), the area reduction was assumed to be $\Delta \mathrm{A}=220 \mathrm{~mm}^{2}$ (Augustyn \& Skotny, 1991). It was assumed that the effect of welding heat coming from two joints can occur simultaneously. That is why the reduction was applied on both sides of the flange, which is shown in Figure 2.

The beam was tested in a four-point bending scheme. The force spacing was $2000 \mathrm{~mm}$, which is presented in Figure 3a. The force of $60 \mathrm{kN}$ was adopted as preload. Together with its own weight, it caused $163 \mathrm{MPa}$ stress in the bottom flange. When stiffness reduction is taken into account, stress at this point increases to $228 \mathrm{MPa}$, which is $97 \%$ of allowable stress. This means that the assumed stress is at a high but safe level during welding. The introduced force was supposed to simulate the load on the structure. It was essential to maintain a constant level of the force through the total time of the test (several hours), also during welding.
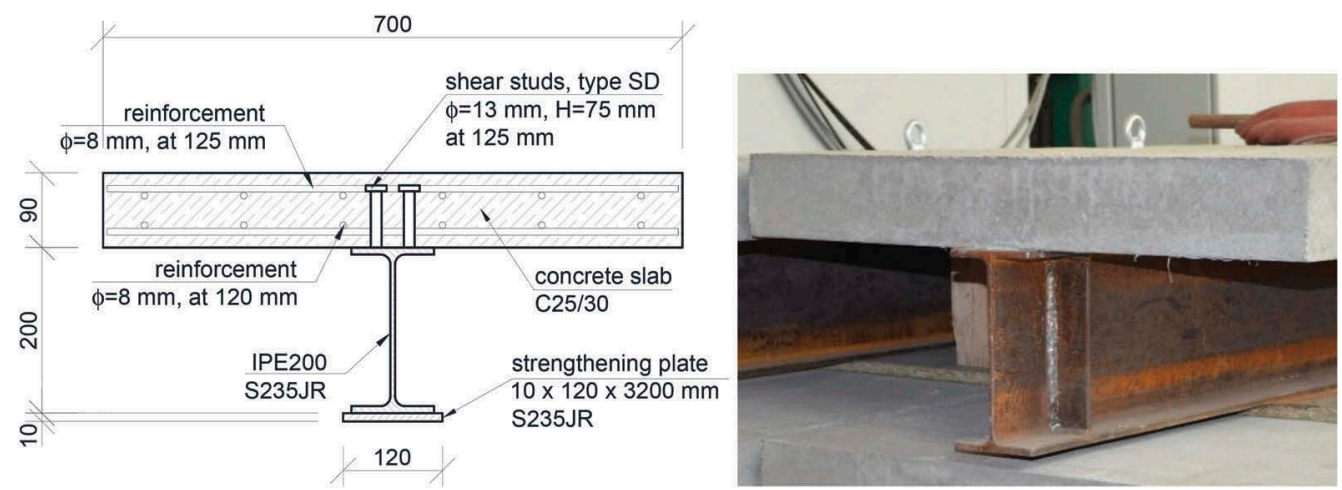

Figure 1. Cross-section of composite beam. 

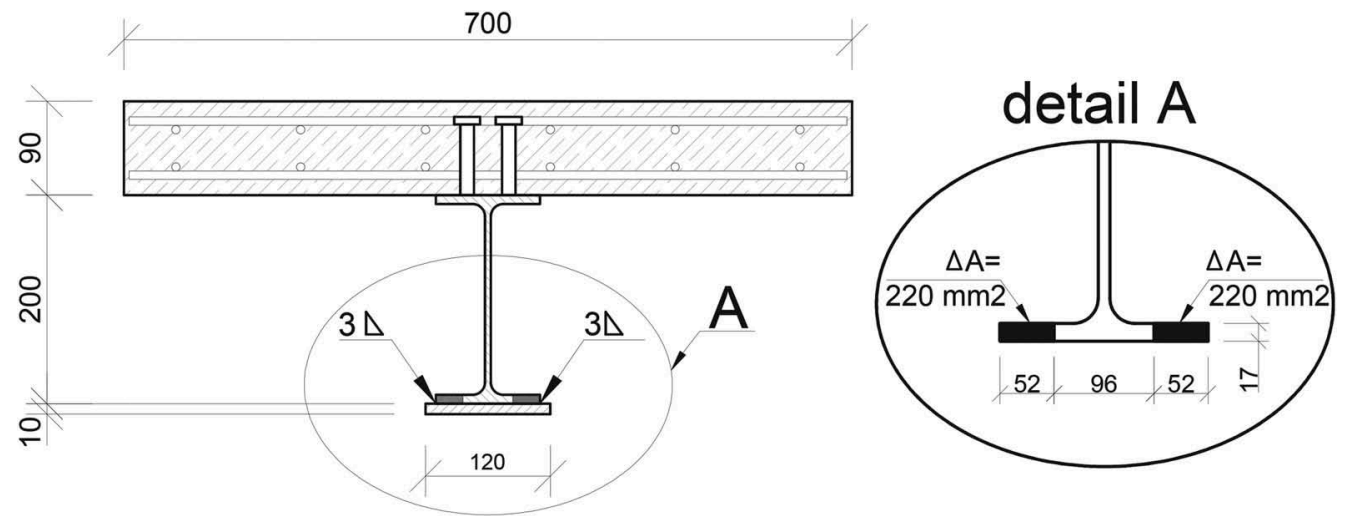

Figure 2. Localization of the cross-sectional area reduction $\Delta \mathrm{A}$.

a)

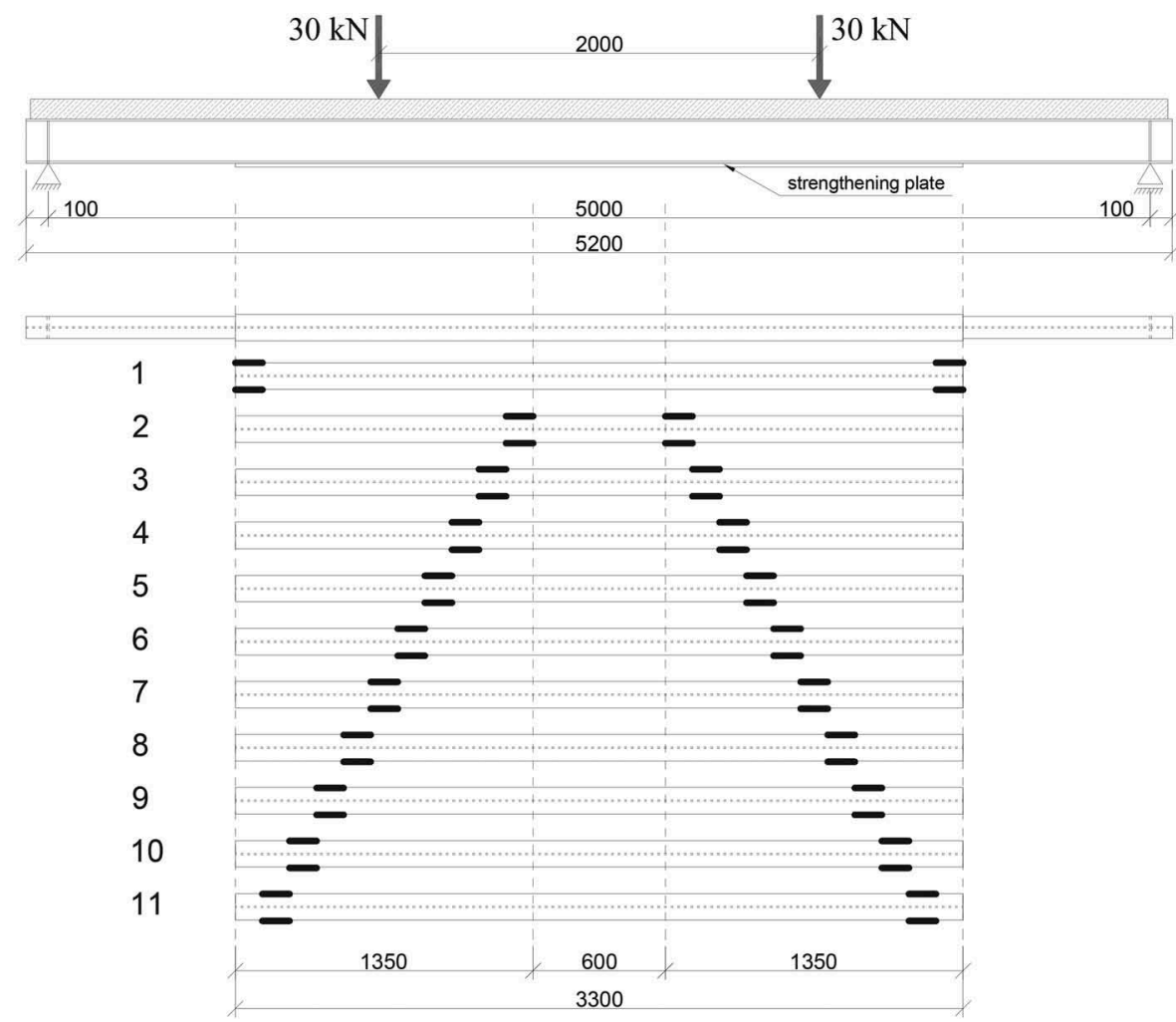

Figure 3. Welding plan, a) beam view, b) the order of making the welds.

Welding through heating up the bottom flange increased its bending. The weld shrinkage caused a reversed direction of deflection. At the same time, the piston had to change its position according to the deflection of the beam, while maintaining a constant, predefined load. The task was completed using a PID precisely preset hydraulic servomotor. Owing to that, force deviation during welding was only $10 \mathrm{~N}$. 


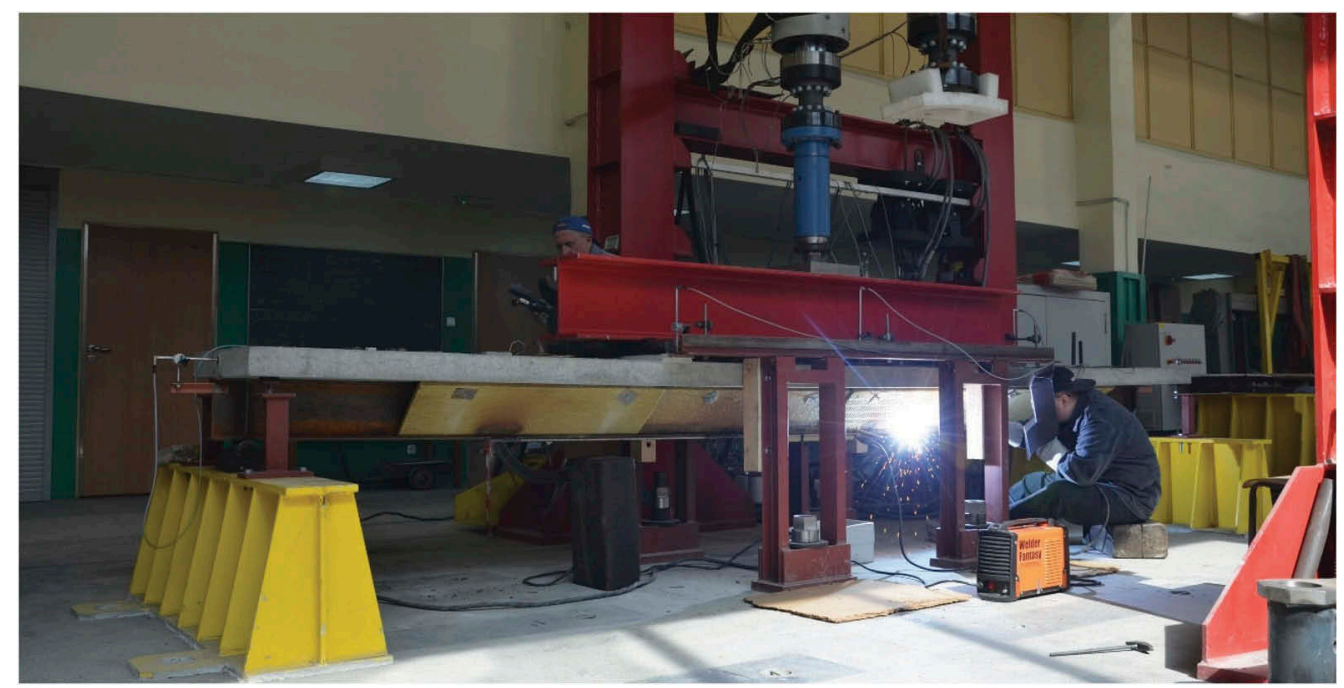

Figure 4. Welding of a strengthening plate.

\subsection{Welding under load}

After the beam completely cooled down and when displacements stabilized, the strengthening sheet metal was put in place. To make sure the sheet metal was close to the beam given its curvature under load, the sheet metal was connected to the bottom flange with steel ties. The welding order is presented in Figure 3b. In line with the guidelines (Augustyn \& Skotny, 1991), (Bródka, 1995), sheet metal ends were welded first. The next welds were done in the order from the middle of the beam towards its ends. Owing to high level of stress where welding was conducted, transverse welds were not done at the end of strengthening sheet metal. As shown, $300 \mathrm{~mm}$ in each direction, i.e. in the vicinity of the beam's middle section, no welds were done to protect strain gauges. The length of individual welds was equivalent to the length of electrodes and equaled approximately $120 \mathrm{~mm}$. Welds were not laid simultaneously but alternately, keeping the symmetry of laid lines. Since welds were done on both sides of the beam, two specialists separately equipped were conducting their welding operations. However, welds were never laid at the same time. Figure 4 shows the model during welding.

\section{RESEARCH RESULTS}

\subsection{Measurements during strengthening}

Vertical displacement in the middle cross-section of the beam was measured during all the test. Displacement values during strengthening are shown in Figure 5. Displacement observed prior to welding process was the effect of preload, defined in Section 2.2. The heating up of the bottom flange during welding increased its deflection. The highest displacement was observed in the first phases of welding when the beam was heated starting from the initial temperature. In the subsequent stages of welding the sheet metal was being connected to the beam and therefore its stiffness was increasing. Also, the first welds started to cool and contract which caused opposite displacement. Therefore, approximately in the middle of strengthening process the measured displacement did not increase so sharply and at the end of it deflection tended to decrease. The latter occurred despite subsequent welds being laid.

All the three graphs of welding show clearly the cycles of displacement increase and decrease caused by heating up and cooling during breaks in the welding process. The strengthening of the first model of the beam took $1.5 \mathrm{~h}$. Following the positive results of the first test, 


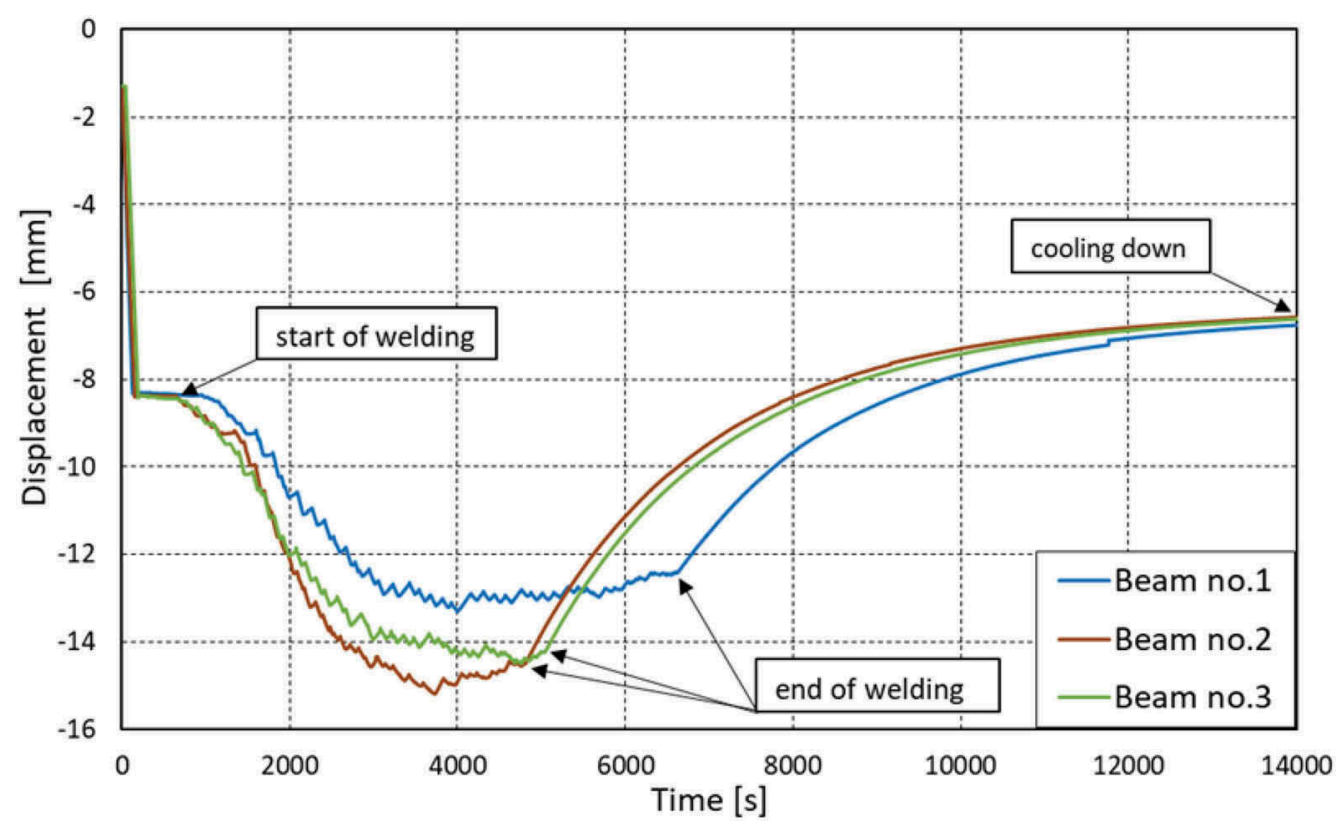

Figure 5. Beam displacement while welding.

the time between laying subsequent welds was shortened, which reduced the total welding time down to $1 \mathrm{~h}$. The Figure 5 shows that welding time, i.e. intensity of heating has clear effect on displacement during strengthening. After cooling, regardless of displacement during welding, deflection of all three beams stabilized at the same level, which is a very important conclusion from the test.

The above process is also presented in Figure 6. It shows displacement recorded for other cross -sections along the beam's axis. The colored dots represent measured values. The solid lines are averaged displacement values. Please note that measurements before and after the welding process are very consistent. Only displacement during welding have greater spread, which is due to different intensity of heating the beams during welding.

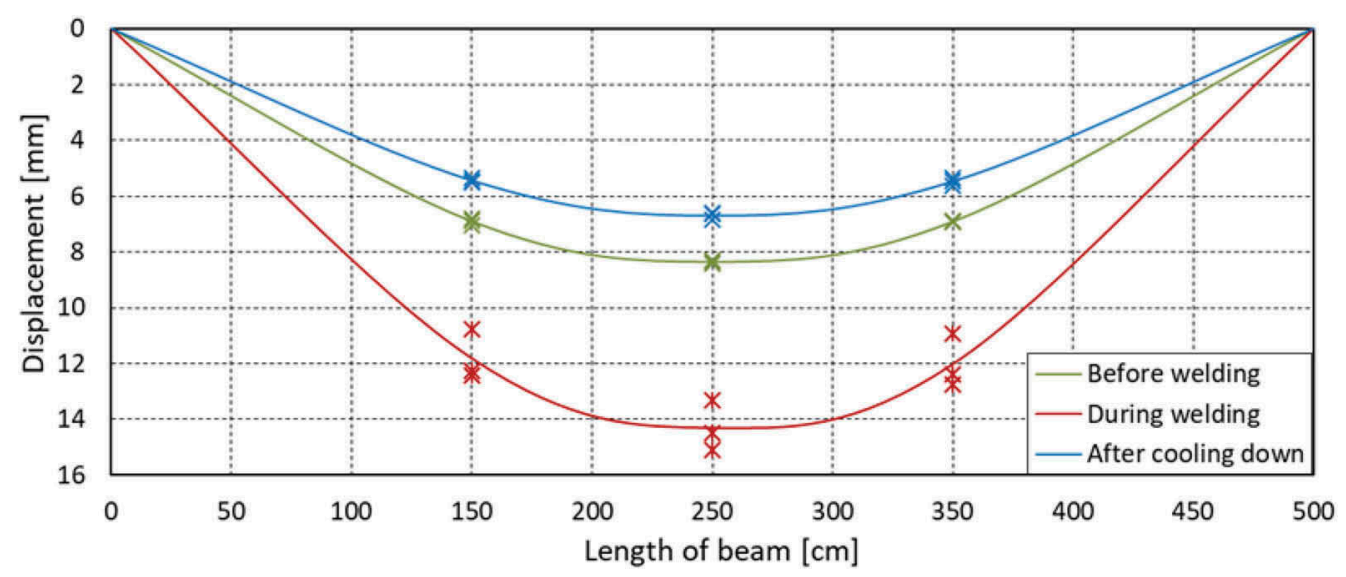

Figure 6. Beam deflection line before, during and after welding. 


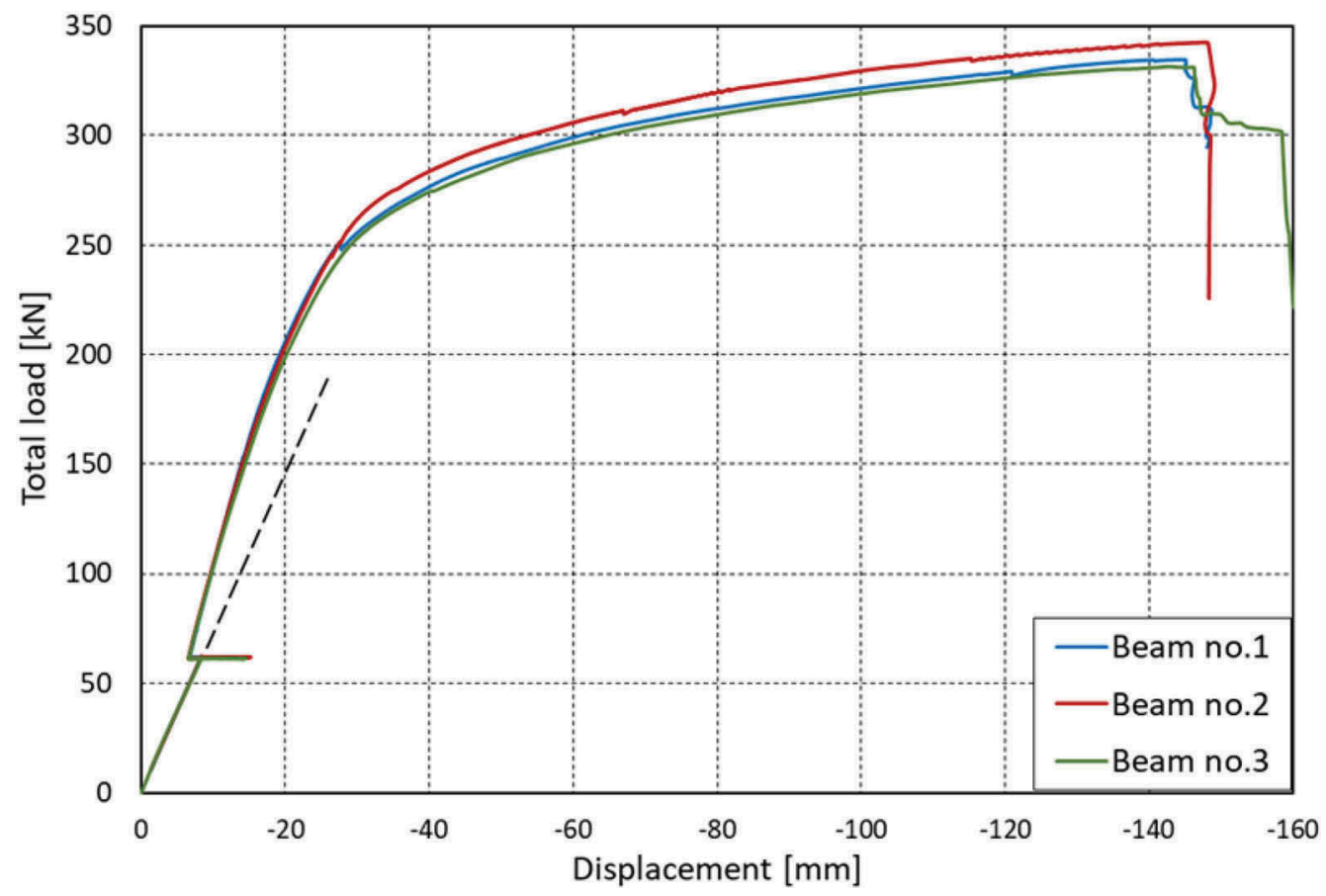

Figure 7. Static equilibrium paths of the strengthened beams.

\subsection{Load increase}

After complete cooling, the next phase of the test was to increase load up to the yield moment and damage of the element. Static equilibrium pathways are a very good tool to present how a structure behaves in all its stages of operation (Szewczyk \& Szumigała, 2019). Accordingly, Figure 7 shows static equilibrium pathways obtained for the analyzed beams. Those are loaddisplacement curves in the middle of the beam's span. For the load of $60 \mathrm{kN}$ (i.e. the load at which strengthening was completed), there are displacement changes at the constant force due to welding and cooling. Those are shown in more detail in Figures 5 and 6.

From then on, there is clear increase of capacity and stiffness, due to the increasing strengthening effect of sheet metal. The graph also shows a dotted line which is a continuation of the initial direction of static equilibrium pathway (without strengthening). Stiffness increase is seen as a change of the inclination angle before and after strengthening.

When the element left the elastic regime of its operation, further load increase led to yield moment, first observed in the outer, stretched steel fibers. It resulted in redistribution of stress in the strengthened and strengthening parts. The further operation in the plastic regime resulted in greater compressive strain in the reinforced concrete slab. Consequently, compressive strength was exceeded and concrete was crushed. It can be seen in the static equilibrium pathway curve as a sudden drop of the force. Shortly before the beam was damaged, high displacement was observed. It was over $140 \mathrm{~mm}$, i.e. 1/35 of the beam's length. Damage was predictable, occurred in a place of the constant bending moment.

\section{CONCLUSIONS}

The paper presents experimental research on a composite beam strengthened by extending the stretched steel part. In operations of this type attention should be paid that the strengthened structure is under load. The consequence of that is e.g. the effect of weld shrinkage which 
occurs during welding operations. In the analyzed case, owing to the location of welds well below the neutral axis, weld shrinkage decreased the beam's deflection, which was a positive effect.

The final displacement of all the welded beams were very similar. However, instantaneous dis-placement due to sudden heating of the structure during welding correlated very strongly with the ratio of welding time and breaks between laying subsequent welds. This is a significant conclusion as for operational or technological reasons the serviceability limit state can be exceeded even for a short time with negative or dangerous consequences.

The presented research is part of a larger project aiming at developing a numerical model of a composite beam strengthened under load.

\section{REFERENCES}

Ali, M. Al, Kvočák, V. \& Platko, P. (2017) Stress State of Steel Column Strengthened under Load, Procedia Engineering, 190, pp. 632-636. doi: 10.1016/j.proeng.2017.05.390.

Augustyn, J. \& Skotny, J. (1991) Tymczasowe wytyczne wzmacniania elementów konstrukcji stalowych przy pomocy spawania pod obciażenieme. Warszawa: Izba Projektowania Budowlanego.

Bródka, J. (1995) Przebudowa i utrzymanie konstrukcji stalowych. Łódź: Mostostal-Projekt, Politechnika Łódzka.

Liu, Y. \& Gannon, L. (2009) Experimental behavior and strength of steel beams strengthened while under load, Journal of Constructional Steel Research, 65(6), pp. 1346-1354. doi: 10.1016/j. jesr.2009.01.008.

Paczkowski, W., Wróblewski, T. \& Skibicki, S. (2020) Skanowanie laserowe stalowej konstrukcji elektrowni węglowej, Builder, 273(4), pp. 22-25. doi: 10.5604/01.3001.0013.8793.

Szewczyk, P. \& Szumigała, M. (2016) Numerical Modelling Of The Strengthening Process Of Steel-Concrete Composite Beams, Civil And Environmental Engineering Reports, 19(4), pp. 99-110. doi: 10.1515/ceer-2015-0056.

Szewczyk, P. \& Szumigała, M. (2019) Static Equilibrium Paths of Steel-Concrete Composite Beam Strengthened Under Load, Civil and Environmental Engineering Reports, 28(2), pp. 101-111. doi: 10.2478/ceer-2018-0022.

Wang, Y. Q. et al. (2015) Behavior of I-section steel beam welding reinforced while under load, Journal of Constructional Steel Research, 106, pp. 278-288. doi: 10.1016/j.jcsr.2014.12.020.

Wierzbicki, K. et al. (2020) Torsional stability assessment of columns using photometry and FEM, Buildings, 10(9). doi: 10.3390/BUILDINGS10090162. 